\title{
微粒子に働く最大静電気力の検討
}

\author{
增 田弘 昭*,松 坂 修 二* \\ Maximum Electrostatic Force acting on a Particle \\ by \\ Hiroaki MASUDA ${ }^{\dagger}$ and Shuji MATSUSAKA ${ }^{\dagger}$
}

Key Words : Electrostatic Force, Fine Particle, Air Breakdown, Saturation Charge, Surface Charge Density

1. はじめに

粉体プロセスでは, 個々の粒子が壁面あるいは周囲 の粒子と接触や衝突を繰り返しており, 静電気によっ て帯電量が著しく増加すると, 操作性能に影響がみら れる。一方, 電気集塵, 静電粉体塗装, 電子写真などの ように, 粒子の帯電性を積極的に利用する技術も進め られているが, 理論的に十分解明されているとは言え ない。一般に, 粒子が小さくなると帯電に基づく静電 気力の影響が強く現われるようになるため, 特に微粒 子の静電気現象が重要といえるが, 粗粒子に对する説 明をそのまま微粒子に適用している場合が多いようで ある。

本報では, 微粒子の気中放電限界に基づく飽和带電 を考慮したときの静電気力を推算し,ファン・デル・ ワールスカをはじめとする他の付着力と比較検討する。

\section{2. 気中放軩限界と最大表面電荷密度}

粗粒子の気中放電限界は電界強度を用いて説明され ているが, 放電限界には二つの異なる基準すなわち電 界と電圧があり, 両方の限界值を超えるときに放電し 始めることが指摘されている1”。電界および電圧に関 する気中放電限界として, それぞれ次の值が用いられ る。

1993年 4月 2日 受付

* 京都大学工学部化学工学教室

( (606-01 京都市左京区吉田本町) TEL. 075-753-5565

$\dagger$ Dept. of Chem. Eng., Kyoto Univ.,

(Yoshida-Honmachi, Sakyo-ku, Kyoto 606-01)

$$
\begin{aligned}
& E_{\mathrm{bk}} \cong 3 \mathrm{MV} \cdot \mathrm{m}^{-1} \\
& V_{\mathrm{bk}} \cong 300 \mathrm{~V}
\end{aligned}
$$

ここで, $V_{\mathrm{bk}}$ はパッシェンの法則2)における絶緑破壊電 圧の最小值に相当する。これらの值は, 平行平板間の 測定結果に基づくものであるが, 飽和带電量の説明に は十分であると考えられている1。

基本的な電気理論に基づいて放電限界に対応する最 大表面電荷密度について以下に検討する。電荷 $q$, 電位 $V$ の粒子が外部電界の動かない空間で孤立していると き, 静電容量 $C$ との間に次式が成立する。

$$
q=C V
$$

粒子を直径 $D_{\mathrm{p}}$ の球形と考えると静電容量は次式で与え られる。

$$
C=2 \pi \varepsilon_{0} D_{\mathrm{p}}
$$

ここで, $\varepsilon_{0}$ は周囲の媒体(空気)の誘電率である。この ときの帯電量 $q$ はEqs. (3), (4) から次式となる。

$$
q=2 \pi \varepsilon_{0} D_{\mathrm{p}} V
$$

また, 粒子表面における電界強度を $E$ とすると $q$ は次 のようにも表わされる。

$$
q=\pi \varepsilon_{0} D_{\mathrm{p}}^{2} E
$$

最大表面電荷密度 $\sigma_{\max }$ は, 電界と電圧に関する気中放電 限界值を用い, Eqs. (5)，（6）を粒子の表面積 $\pi D_{\mathrm{p}}^{2}$ で割 ることによって求めることができる。すなわち， 


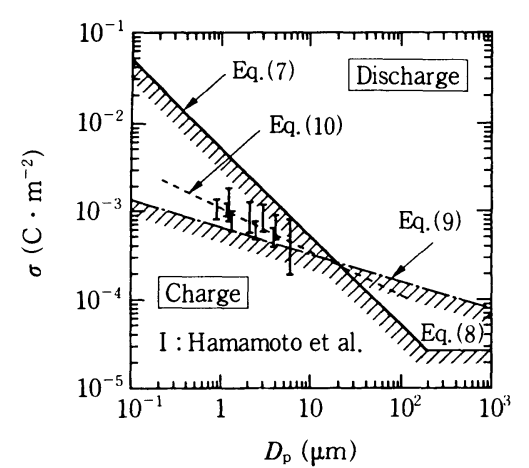

Fig. 1 Relationship between surface charge density and particle diameter

$$
\begin{aligned}
& \sigma_{\max }=2 \varepsilon_{0} V_{\mathrm{bk}} / D_{\mathrm{p}} \quad\left(D_{\mathrm{p}} \leqq 2 \times 10^{-4} \mathrm{~m}\right) \\
& \sigma_{\max }=\varepsilon_{0} E_{\mathrm{bk}} \quad\left(D_{\mathrm{p}} \geqq 2 \times 10^{-4} \mathrm{~m}\right)
\end{aligned}
$$

粒子径 $D_{\mathrm{p}}=2 \times 10^{-4} \mathrm{~m}$ のとき, Eq. (7) とEq. (8)の $\sigma_{\max }$ は等しい。すなわち, 粒子径が $200 \mu \mathrm{m}$ 以上ではEq. (8)で, $200 \mu \mathrm{m}$ 以下ではEq. (7) で最大表面電荷密度が決 まる。

一方, Harper $^{31}$ は, 線電極の放電限界値を微小粒子に 適用したSchumannの報告をもとにして, 微小粒子の 最大表面電荷密度 $\sigma_{\max }$ を次のように表わした。

$$
\sigma_{\max }=a_{1} D_{\mathrm{p}}^{-0.3} \quad\left(a_{1} \cong 1.03 \times 10^{-5}\right)
$$

また, 濱本ら"は微小液滴の表面電荷密度を実験的に 求めており, 各条件において得られた結果の分布を考 虑して, 最大頻度における表面電荷密度を評価した。 このときの関係は次の実験式で表わされる。

$$
\sigma=a_{2} D_{\mathrm{p}}^{-0.5} \quad\left(a_{2} \cong 1.2 \times 10^{-6}\right)
$$

Eqs. (7)，(8)，(9)，(10)の計算結果および実験結果 をFig. 1に示す。乾燥空気の誘電率は $\varepsilon_{0}=8.85 \times 10^{-12}$ $\mathrm{F} \cdot \mathrm{m}^{-1}$ とした。微粒子では, いずれの関係式におい ても粒径が小さくなるほど表面電荷密度が大きくなる ことがわかる。実験值は, ほぼEq. (7) とEq. (9)の間 に分布しているが, 濱本らは実験值に非持続性の放電 効果が含まれていると考察しており, 最大表面電荷密 度は実験值より多少大きくなるものと予想される。し たがって, 最大表面電荷密度の推算としてEqs. (9), （10）は過小評価となり, Eq. (7)の方が近似式として妥 当であると考えられる。

\section{3. 粒子間相互作用力}

2 粒子の中心間距離を $r$, 粒子の電荷をそれぞれ $q_{1}$, $q_{2}$ とすると, 粒子間に作用する静電気力は次式で与え
られる。

$$
F_{\mathrm{e}}=\frac{1}{4 \pi \varepsilon_{0}} \frac{q_{1} q_{2}}{r^{2}}
$$

二つの球形粒子(誘電体) が接触しており, 粒子表面間 距離 $z$ が $z$ « $D_{\mathrm{p}}$ とすると, Eq. (11)は次のように表わ される。

$$
F_{\mathrm{e}}=\frac{\pi \sigma_{1} \sigma_{2}}{\varepsilon_{0}}\left(\frac{D_{\mathrm{p} 1} D_{\mathrm{p} 2}}{D_{\mathrm{p} 1}+D_{\mathrm{p} 2}}\right)^{2}
$$

ここで, $\sigma_{1}$ と $\sigma_{2}$ は各粒子の表面電荷密度である。静電気 力の最大值 $\boldsymbol{F}_{\mathrm{emax}}$ は, 電荷が互いに反对符号で, 最大表面 電荷密度に達しているとぎであり，Eq. (12)にEq. (7)あるいは(8)を代入することにより，それぞれ次 のように得られる。

$$
\begin{aligned}
F_{\mathrm{emax}}= & -4 \pi \varepsilon_{0} V_{\mathrm{bk}}{ }^{2} \frac{D_{\mathrm{p} 1} D_{\mathrm{p} 2}}{\left(D_{\mathrm{p} 1}+D_{\mathrm{p} 2}\right)^{2}} \\
& \left(D_{\mathrm{p} 1}, D_{\mathrm{p} 2} \leqq 2 \times 10^{-4} \mathrm{~m}\right) \\
F_{\mathrm{emax}}= & -\pi \varepsilon_{0} E_{\mathrm{bk}}{ }^{2}\left(\frac{D_{\mathrm{p} 1} D_{\mathrm{p} 2}}{D_{\mathrm{p} 1}+D_{\mathrm{p} 2}}\right)^{2} \\
& \left(D_{\mathrm{p} 1}, D_{\mathrm{p} 2} \geqq 2 \times 10^{-4} \mathrm{~m}\right)
\end{aligned}
$$

粒子径が等しいとき $\left(D_{\mathrm{p}}=D_{\mathrm{p} 1}=D_{\mathrm{p} 2}\right)$, Eqs. (13), (14) はそれぞれ次のようになる。

$$
\begin{array}{ll}
F_{\text {emax }}=-\pi \varepsilon_{0} V_{\mathrm{bk}^{2}} & \left(D_{\mathrm{p}} \leqq 2 \times 10^{-4} \mathrm{~m}\right) \\
F_{\text {emax }}=-\frac{\pi \varepsilon_{0} E_{\mathrm{bk}}{ }^{2}}{4} D_{\mathrm{p}}^{2} & \left(D_{\mathrm{p}} \geqq 2 \times 10^{-4} \mathrm{~m}\right)
\end{array}
$$

一方, ファン・デル・ワールスカ $F_{\mathrm{v}}$ は, Hamaker 定数を $A$ とすると次式で与えられる。

$$
F_{\mathrm{v}}=-\frac{A D_{\mathrm{p}}}{24 z^{2}}
$$

式中の負記号は引力を表わしている。粒子の接触部に おいて弾性変形が生じることを考虑すると次のように なる5)。

$$
F_{\mathrm{v}}=-\frac{A D_{\mathrm{p}}}{24 z^{2}}\left(1+\frac{A^{2} k^{2} D_{\mathrm{p}}}{216 z^{7}}\right)
$$

ただし, $k$ は次式で定義される弾性特性定数である。

$$
k=\frac{1-v_{1}^{2}}{E_{1}}+\frac{1-v_{2}^{2}}{E_{2}}
$$

*たとえば，ある粉体に仕事関数が大きく異なる少量の粉体を搅拌 によって混合する場合や, 飽和带電粒子が金属壁面近くで電気影 像効果を受ける場合などが考えられる。 
ここで, $v_{1}, v_{2}$ は各粒子のポアソン比, $E_{1}, E_{2}$ はヤング 率である。

また, 液架橋力 $F_{\mathrm{c}}$ は, 液と粒子の接触角をゼロとし， 液架橋の大きさが粒子径に比べて十分小さいとすると 次式で表わされる。

$$
F_{\mathrm{c}}=-\pi \gamma D_{\mathrm{p}}
$$

静電気力, ファン・デル・ワールスカ, 液架橋力の 大きさを比較検討するためにEqs.(15)，(16)，(17)， (18)，(20)の計算結果を Fig. 2に示す。粒子径によっ て付着力の支配要因は変化するが, 放電限界に達する まで十分に帯電したミクロンオーダー以下の微粒子で は，静電気力が支配的であることがわかる。ただし， これは乾燥雲囲気を想定したものであり，高湿度にな ると放電限界值が低下するため飽和帯電量が減少し, したがって液架橋力が支配的となる。また，高分子材 料のように比較的弾性変形を起しやすい粒子では, $10 \mu \mathrm{m}$ 以上においてファン・デル・ワールスカが支配 的となることがわかる。なお, 弾性変形による粒子の 中心間距離の変化を考慮すると, 静電気力 (クーロン 力）は粒子径の減少とともに少しずつ大きくなる傾向 にあるが,ミクロンオーダー以上ではこの影響はほと んど無視できる。

ところで, 粒子の表面粗さが増加するとファン・デ ル・ワールスカのような近接力は著しく低下するが, 静電気力のような場の力は変化しないため, 静電気力 の影響が相対的に大きくなることが予想される。表面 粗さ $b$ を考虑したファン・デル・ワールスカは, 近似 的に次式で与えられる。

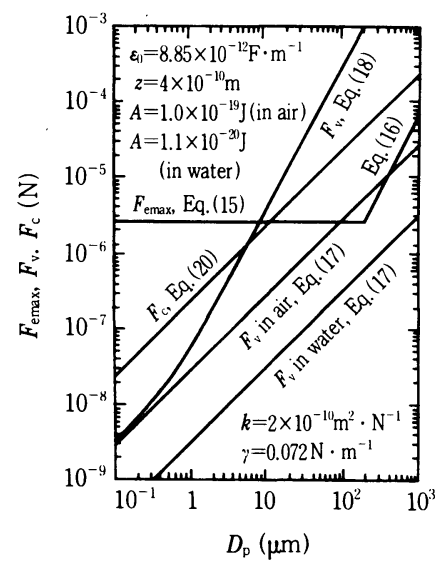

Fig. 2 Calculated values of interaction force between particles

$$
F_{\mathrm{vb}}=-\frac{A D_{\mathrm{p}}}{24(z+b)^{2}}
$$

また, ファン・デル・ワールスカは, $z+b か ゙ 10 \mathrm{~nm} の$ オーダ一以上になると遅延効果を考慮する必要があ $\eta,(z+b) \ll D_{\mathrm{p}}$ のときには, Gregory $\left.{ }^{6}\right)$ が提案したポ テンシャルエネルギーの近似式から次のように誘導 される。

$$
F_{\mathrm{vb}}=-\frac{A \lambda D_{\mathrm{p}}}{24\{c(z+b)+\lambda\}(z+b)^{2}}
$$

ただし，定数 $c$ は5.32であり，波長 $\lambda$ は100nmとす る。Eqs. (15), (16)およびEq. (22) から次の関係式が 得られる。

$$
\begin{gathered}
F_{\mathrm{emax}} / F_{\mathrm{vb}}=\frac{24 \pi \varepsilon_{0} V_{\mathrm{bk}}{ }^{2}\{c(z+b)+\lambda\}(z+b)^{2}}{A \lambda D_{\mathrm{p}}} \\
\left(D_{\mathrm{p}} \leqq 2 \times 10^{-4} \mathrm{~m}\right) \\
F_{\text {emax }} / F_{\mathrm{vb}}=\frac{6 \pi \varepsilon_{0} E_{\mathrm{bk}}{ }^{2}\{c(z+b)+\lambda\}(z+b)^{2} D_{\mathrm{p}}}{A \lambda} \\
\left(D_{\mathrm{p}} \geqq 2 \times 10^{-4} \mathrm{~m}\right)
\end{gathered}
$$

Eqs. (23), (24)の計算結果をFig. 3に示す。静電気力 とファン・デル・ワールスカの比は, 粒子径に対する 表面粗さの割合 $b / D_{\mathrm{p}}$ を一定にすると, 粒子径に対し て極小值をもつことがわかる。また, 気中放電限界の 基準の違いから, 粒子径 $D_{\mathrm{p}}=200 \mu \mathrm{m}$ を境に変化の傾向 は異なるが, 粒子の表面粗さが大きくなるほど静電気 力が支配的となることがわかる。本計算条件では, 表

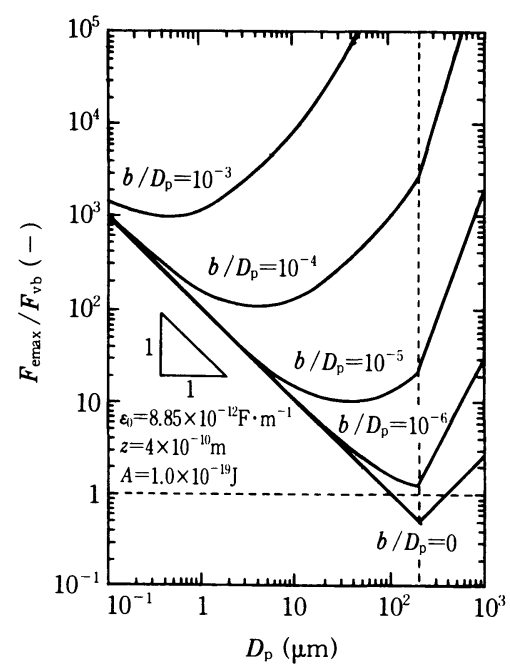

Fig. 3 Effect of surface roughness on ratio of electrostatic force $F_{\text {emax }}$ to van der Waals force $F_{\mathrm{vb}}$ 
面粗さが粒子径の $1 / 10^{6}$ 以上において，いかなる粒子 径においても静電気力の方がファン・デル・ワール スカより大きくなり, 仮に, Hamaker定数が10倍にな ったとしても, 表面粗さが粒子径の $1 / 10^{5}$ 以上で静電 気力の方が支配的となる。実際の粒子の表面粗さはこ れらの值より大きいことが多く, 十分に帯電した粒子 では, 静電気力による影響を受けやすいといえる。

\section{4. 結 論}

1） $200 \mu m 以 下 の$ 粒子の最大表面電荷密度は, 電圧に
関する気中放電限界值を考慮する方法によって近似的 に求められることが, 既往の実験結果との比較から確 認された。これによって, 粒子径の減少とともに最大 表面電荷密度が大きくなる現象が説明される。

2）ミクロンオーダー以下の微粒子が十分に帯電す ると, 静電気力は液架橋力やファン・デル・ワールス 力よりも大きくなり得る。また, 粒子の表面粗さが増 加するとファン・デル・ワールスカよりも静電気力 による付着力の方が一層大きくなる。

\section{Nomenclature}

A : Hamaker constant

$a_{1}$ : constant in Eq. (9)

$a_{2}$ : constant in Eq. (10)

$b \quad$ : surface roughness of particle

C : capacitance

c : constant in Eq. (22)

$D_{\mathrm{p}}, D_{\mathrm{p} 1}, D_{\mathrm{p} 2}:$ particle diameter

$E \quad$ : electric field

$E_{\text {bk }}:$ critical electric field for air break down

$E_{1}, E_{2}$ : Young's modulus

$F_{\mathrm{c}} \quad$ : liquid bridge force

$F_{\mathrm{e}}$ : electrostatic force

$F_{\text {emax }}$ : maximum electrostatic force
(J) $\quad F_{\mathrm{v}}$ : van der Waals force (smooth surface)

$\left(\mathrm{C} \cdot \mathrm{m}^{-1.7}\right) \quad F_{\mathrm{vb}}$ : van der Waals force (rough surface)

$\left(\mathrm{C} \cdot \mathrm{m}^{-1.5}\right)$

$k \quad$ : quantity defind by Eq. (19)

$q, q_{1}, q_{2}:$ charge

$r \quad$ : distance between particles

$V \quad$ : voltage

(m) $\quad V_{\mathrm{bk}}$ : critical voltage for air breakdown

$\left(\mathrm{m}^{2} \cdot \mathrm{N}^{-1}\right)$

$z$ : separation distance

$$
\left(\mathrm{V} \cdot \mathrm{m}^{-1}\right)
$$

$\left(\mathrm{V} \cdot \mathrm{m}^{-1}\right)$

$\gamma \quad$ : surface tension

$\varepsilon_{0} \quad$ : permittivity

$\left(\mathrm{N} \cdot \mathrm{m}^{-2}\right)$

(N)

$\lambda \quad$ : characteristic wavelength

$v_{1}, v_{2}$ : Poisson ratio

$\left(\mathrm{N} \cdot \mathrm{m}^{-1}\right)$

$\left(\mathrm{F} \cdot \mathrm{m}^{-1}\right)$

(m)

$(-)$

(N) $\quad \sigma_{\max }:$ maximum surface charge density

\section{References}

1) Crowley, J. M. : "Fundamentals of applied electrostatics”, pp. 3 38, John Wiley \& Sons (1984)

2) Seidenki Gakkai (ed.) : "Handbook of Electrostatics”, p. 215, Ohmu Sha (1981)

3) Harper, W. R. : "Contact and Frictional Electrification”, pp. 14 15, Oxford Univ. Press
(1967)

4) Hamamoto, N., Y. Nakajima and T. Sato : Proceedings Institute Electrostatics Japan, 15, 452 (1991)

5) Dahneke, B. : J. Colloid Interface Sci., 40, 1 (1972)

6) Gregory, J. : J. Colloid Interface Sci., 83, 138 (1981) 